\title{
Review
} Avaбкóтпбฤ

\section{Aggravating factors and assessment tools for Posttraumatic Stress Disorder in children after hospitalization}

\author{
Chr. Triantafyllou, ${ }^{1}$ V. Matziou ${ }^{2}$ \\ ${ }^{1}$ Center for Clinical Epidemiology and Outcomes Research (CLEO), Athens, \\ ${ }^{2}$ Department of Nursing, National and Kapodistrian University of Athens, Athens, Greece \\ Psychiatriki 2019, 30:256-266
}

\begin{abstract}
osttraumatic stress disorder (PTSD) is a mental disorder caused by several distressing events that are related with psychotrauma. It is very frequent in childhood and untreated traumatic stress symptoms in children and adolescents often result in debilitating consequences on development with increased risks for a variety of physical and mental disorders. It has been found that PTSD symptoms are reduced as soon as therapeutic interventions have been applied. The aim of the present review was to summarize the available literature regarding aggravating factors associated with the development of PTSD in children after hospitalization and assessment tools for a quick and reliable screening of children who are at risk for developing PTSD. A review of published papers was conducted until April 10, 2019 to identify articles that discuss the aggravating factors and the assessment tools for PTSD in children after hospitalization published in English, German or Greek language. Search was performed on PubMed with the following combination of key-words: "PTSD" and "children" and "hospitalization", using the filters "human" and "Publication date from 30/11/2007 to 09/04/2019" and choosing "all fields" in PubMed Advanced Search Builder. Of the 115 articles reviewed, 16 relevant articles were included, 10 of them referred to the aggravating factors and the remaining 6 were related to the assessment tools. Significant aggravating factors associated with the development of PTSD were: traumatic injuries and illness/ medical-related hospital admission, previous health problems, Pediatric Intensive Care Unit (PICU) hospitalization, attendance at a hospital for child and adolescent psychiatry, female gender and psychotherapy and initial high Posttraumatic Stress Symptoms (PTSS) in parents. As for assessment tools, it was observed that the Child Trauma Screening Questionnaire (CTSQ)-Heart Rate (HR), the alternative PTSD algorithm (PTSD-AA), the Child Stress Disorders Checklist-Short Form (CSDC-SF), the Diagnostic and Statistical Manual of Mental Disorders, 4th Edition (DSM-IV) model for PTSD symptom categories, the Posttraumatic Stress Disorder Semi-Structured Interview (PTSDSSI), the
\end{abstract}


Preschool Children's Assessment of Stress Scale (PCASS) and the diagnostic interview for children and adolescents (DICA-P) led to the identification of children who were likely to develope or had already developed PTSD symptoms, in the study population wherein each was implemented. The greatest limitation - but also a significant finding - of this review is the scarceness of published studies on this topic. Overall, there is a variety of aggravating factors associated with the development of PTSD in children after hospitalization. Assessment tools should be able to identify immediately the children who are likely to or have already developed PTSD symptoms.

Key words: PTSD, children, aggravating factors, assessment tools, hospitalization.

\section{Introduction}

Hospitalization has been associated with a variety of adverse psychological events in pediatric patients, including posttraumatic stress symptoms at both diagnostic (PTSD) and subsyndromal levels (posttraumatic stress symptoms: PTSS). ${ }^{1,2}$ PTSD is associated with traumatic injuries or illness/medicalrelated hospital admission, with prevalence rates of clinically elevated levels of posttraumatic distress ranging from $6 \%$ to $45 \%$ following trauma such as falls and burns and 5 to $32 \%$ following medical-related hospital admission, such as cardiac surgery. ${ }^{1,3}$ Moreover, factors related to the general experience of hospitalization, such as invasive medical procedures, lack of sleep and separation from parents may also be distressing and could lead to the development of PTSD.

It has been shown that untreated traumatic stress symptom in children may persist for years, even into adulthood, often having destructively consequences on their development. ${ }^{4}$ For instance, PTSD has been associated with decreased total and cerebral brain volume and attenuated frontal lobe asymmetry. ${ }^{5,6}$ Moreover, PTSD increases the risk for a variety of physical and mental disorders, including circulatory, endocrine, musculoskeletal and digestive diseases, substance abuse, eating disorders and depression. ${ }^{7}$ Although there are many interventions that have been shown to significantly reduce PTSD symptoms in traumatized children, their effectiveness may be decreased as time from trauma exposure elapses. ${ }^{8-10}$ This finding indicates a reasonable need for assessment tools that can accurately assess traumatic stress symptoms in at-risk children, immediately after the trauma exposure.
What is more, these assessment tools should be accessible to health professionals working in settings where injured or medically ill children are treated such as emergency rooms and medical inpatient units. Particularly, measures should (a) be short enough to be easily integrated into numerous acute clinical settings, (b) based on sources readily available and (c) require minimal training to administer and interpret. ${ }^{11}$

The purpose of the current review was to summarize the available literature regarding aggravating factors associated with the development of PTSD in children after hospitalization and assessment tools for a quick and reliable screening of children who are at risk for developing PTSD.

\section{Material and method}

A review of published papers was conducted until April 10, 2019 to identify articles that discuss the aggravating factors associated with the development of PTSD in children after hospitalization and assessment tools for screening the children who are at risk for developing PTSD. Search was performed on PubMed with the following combination of key-words: "Posttraumatic stress disorder" and "children" and "hospitalization", using the filters "human" and "Publication date from 30/11/2007 to 09/04/2019" and choosing "all fields" in PubMed Advanced Search Builder. Studies were excluded if they:

- were case studies, editorials and letters to the editors;

- were not published in English, German and Greek language;

- did not refer to the aggravating factors and the assessment tools; or 
- focused solely on parents and/or did not include findings on children.

All the articles were read and evaluated by two independent reviewers (CT, VM) in order to determine applicability for inclusion. Out of the 115 articles reviewed, 16 relevant articles were finally included in this review.

\section{Results}

Of the 16 studies reviewed, 10 referred to the aggravating factors ${ }^{12-21}$ (table 1) and the remaining 6 were related to the assessment tools (table 2).

\section{Aggravating factors}

A comparison study ${ }^{12}$ investigated and compared psychological responses in children 1 month after traumatic injuries or illness/medical-related hospital admission. This study concluded that clinically elevated PTSD symptom levels were more frequent in children admitted for traumatic injuries (18\%) than illness/medical-related causes (4\%) and there was a significant relationship (positive) between length of stay and the development of PTSD. Another study ${ }^{13}$ examined the prevalence of PTSD in pediatric burn survivors who had been treated for acute stress disorder (ASD) symptoms during their initial hospitalization and compared them with patients who had been asymptomatic for ASD symptoms and found that the prevalence of PTSD was similar in children with ASD symptoms and those without ASD symptoms.

Moreover, according to Bruce et $\mathrm{al}_{1}{ }^{14}$ greater endorsement of both monitoring and blunting attentional coping styles were significantly correlated with elevated PTSS in childhood brain tumor survivors $(B=0.24, p=0.01$ and $\beta=0.18, p=0.02$, respectively). Furthermore, a study ${ }^{15}$ that explored the risk of PTSD development and PTSS in patients at a hospital for child and adolescent psychiatry and psychotherapy, came to the conclusion that almost one of four patients of child mental health service could be identified with clinically significant PTSS. A systematic review ${ }^{16}$ examined the research literature on children's psychological responses to PICU hospitalization, showed that increased parental distress, length of PICU stay, delusional memories and emergency admission were possible aggravating factor for PTSD.

What is more, according to Landolt et al, ${ }^{17}$ children with injuries had higher rates of PTSS than children with diabetes and cancer and initially high levels of PTSS in mothers and fathers were longitudinally related to poorer remission of PTSS in the child. A cohort study ${ }^{18}$ concluded that the past health problems and sepsis were significant independent predictors of PTSS in children aged 5-16 years old admitted to intensive care with meningoencephalitis, sepsis and other critical illnesses $(p<0.04)$.

Another study ${ }^{19}$ showed that younger age, admission for traumatic injury and cognitive/affective factors including confusion, peritrauma panic, and sensory memory quality were associated with acute PTSS following PICU admission. Furthermore, Stowman et $\mathrm{al}^{20}$ examined the potential mediators of later PTSS following PICU hospitalization and showed that youth acute stress disorder symptoms (ASDS), parent ASDS, youth anxiety, negative affect and hospital fear mediated later youth PTSS. Last but not least, a meta-analysis ${ }^{21}$ concluded that the female children and adolescents who exposed to interpersonal traumatic injury are in particular risk of developing PTSD after traumatic injury.

\section{Assessment tools}

In 2010, a study 22 was published which (1) examined PTSD symptom structure in two samples of children (8 to 17 years of age) assessed an average of 6 months after unintentional injury: a combined dataset of 479 children assessed with a PTSD symptom checklist and a sample of 204 children assessed via a standardized clinical interview, (2) evaluated the fit of six alternative models for the factor structure of PTSS and the association of PTSS clusters with indicators of functional impairment and (3) evaluated three models for the structure of PTSD and depression symptoms jointly to examine specificity of PTSD versus general distress or mood symptoms.

The PTSD symptom checklist used in the first sample was the Child PTSD Symptom Scale (CPSS), ${ }^{23}$ which is a 24-item self-report instrument that yields both a PTSD symptom severity score and a determi- 
Table 1. Aggravating factors associated with the development of PTSD in children after hospitalization/

\begin{tabular}{|c|c|c|}
\hline Authors & Objective & Sample \\
\hline Murray et $\mathrm{al}^{12}$ & $\begin{array}{l}\text { Investigation of psychological } \\
\text { responses in children one } \\
\text { month after traumatic injuries } \\
\text { and illness/medical -related } \\
\text { hospital admission }\end{array}$ & 205 children (aged 7-16 years) \\
\hline $\begin{array}{l}\text { Rosenberg } \\
\text { et } \mathrm{al}^{13}\end{array}$ & $\begin{array}{l}\text { Examination of the prevalence } \\
\text { of PTSD in pediatric burn } \\
\text { survivors }\end{array}$ & 183 participants \\
\hline Bruce et $a^{14}$ & $\begin{array}{l}\text { the exploration of the rela- } \\
\text { tionship between objective } \\
\text { illness parameters, parent- } \\
\text { child interactions, coping } \\
\text { styles and PTSS }\end{array}$ & $\begin{array}{l}62 \text { brain tumour survivors } \\
\text { (8 to16 years old) }\end{array}$ \\
\hline Münzer et $\mathrm{al}^{15}$ & $\begin{array}{l}\text { Exploration of PTSS of patients } \\
\text { attending a hospital for child } \\
\text { and adolescent psychiatry } \\
\text { and psychotherapy }\end{array}$ & $\begin{array}{l}413 \text { children and adolescents } \\
\text { at their first attendance at } \\
\text { the clinic }\end{array}$ \\
\hline $\begin{array}{l}\text { Rennick and } \\
\text { Rashotte }^{16}\end{array}$ & $\begin{array}{l}\text { Children's psychological out- } \\
\text { comes following PICU hospi- } \\
\text { talization }\end{array}$ & 28 papers \\
\hline
\end{tabular}

Landolt et al $^{17}$

Als et $\mathrm{al}^{18}$

Dow et al $^{19}$

Stowman et $\mathrm{al}^{20}$

Alisic et $\mathrm{al}^{21}$
Examination of the presence of PTSS and PTSD in children and the mutual influence of child and parental PTSS
287 children (aged 6.5-16 years), their mothers $(n=239)$ and fathers $(n=221)$
Investigation of basal cortisol 47 cases and 56 healthy conregulation in 5-16 years old trols children, 3-6 months following PICU admission

Association between premor- 95 children aged 6-16 years bid, trauma, and cognitive/ affective variables acute PTSS following PICU admission.

Results

Clinically elevated PTSD symp-
tom levels were more preva-
lent in children admitted for
traumatic injuries (18\%) than
illness/medical reasons (4\%)
The prevalence of PTSD was
similar in children with and
without ASD symptoms

Greater endorsement of both monitoring and blunting attentional coping styles were significantly correlated with elevated PTSS

Clinically relevant PTSS were reported in $22.9 \%$ of the children and adolescents

Increased parental distress, length of PICU stay, delusional memories and emergency admission were possible aggravating factors for PTSD

Children with injuries had higher rates of PTSS than children with diabetes and cancer and initially high levels of PTSS in mothers and fathers were related to poorer recovery of PTSS in the child

Past health problems and sepsis were significant independent predictors

Younger age, admission for traumatic injury and cognitive/affective factors were associated with acute PTSS

Youth ASDS, parent ASDS, youth anxiety, negative affect and hospital fear mediated later youth PTSS

Female gender and interpersonal traumatic injury are significant aggravating factors of PTSD in traumatic injury- 43 independent samples exposed children and ado- $(n=3,563)$ lescents

PTSD: Posttraumatic stress disorder, ASD: Acute stress disorder, PTSS: Posttraumatic stress symptoms, PICU: Pediatric intensive care unit, ASDS: Acute stress disorder symptoms 
Table 2. Assessment tools for a quick and reliable screening of children who are at risk for developing PTSD.

\begin{tabular}{|c|c|c|c|}
\hline Authors & Objective & Sample & Results \\
\hline $\begin{array}{l}\text { Kassam-Adams } \\
\text { et } \mathrm{al}^{22}\end{array}$ & $\begin{array}{l}\text { Examination of the factor struc- } \\
\text { ture of PTSS in children and } \\
\text { adolescents who had expe- } \\
\text { rienced an acute single-inci- } \\
\text { dent trauma }\end{array}$ & $\begin{array}{l}\text { Two samples of children (479 } \\
\text { and } 204 \text { respectively. } 8 \text { to } 17 \\
\text { years of age) assessed an } \\
\text { average of } 6 \text { months after } \\
\text { unintentional injury }\end{array}$ & $\begin{array}{l}\text { The DSM-IV model for PTSS } \\
\text { categories was a reasonable } \\
\text { fit for these child data, but } \\
\text { several alternative models fit } \\
\text { equally well or better }\end{array}$ \\
\hline Olsson et $\mathrm{al}^{27}$ & $\begin{array}{l}\text { Investigation of the utility of the } \\
\text { CTSQ plus HR to identify chil- } \\
\text { dren likely to develop PTSS at } \\
1 \text { and } 6 \text { months post-injury }\end{array}$ & 79 children (aged 7-16 years & $\begin{array}{l}\text { CTSQ-HR was better than the } \\
\text { CTSQ or HR alone at identify- } \\
\text { ing children likely to develop } \\
\text { PTSS }\end{array}$ \\
\hline Enlow et $\mathrm{al}^{30}$ & $\begin{array}{l}\text { The development of a user- } \\
\text { friendly scale that measures } \\
\text { traumatic stress responses in } \\
\text { injured children. }\end{array}$ & $\begin{array}{l}147 \text { children and adolescents } \\
\text { (ages } 6-18 \text { ) hospitalized with } \\
\text { burns or acute injuries }\end{array}$ & $\begin{array}{l}\text { The CSDC-SF demonstrated } \\
\text { test-retest reliability and pre- } \\
\text { dictive validity comparable to } \\
\text { that of the full scale }\end{array}$ \\
\hline Dow et $a^{32}$ & $\begin{array}{l}\text { Exploration of PTSD in children } \\
\text { and adolescents following } \\
\text { PICU admission }\end{array}$ & $\begin{array}{l}59 \text { children aged } 6-16 \text {, admit- } \\
\text { ted to PICU for at least } 8 \\
\text { hours }\end{array}$ & $\begin{array}{l}\text { The PTSD-AA was found to } \\
\text { provide the most valid mea- } \\
\text { sure of PTSD at } 6 \text { months }\end{array}$ \\
\hline Ari et $a^{35}$ & $\begin{array}{l}\text { Assessment of the frequency } \\
\text { and characteristics of symp- } \\
\text { toms of persistent psycho- } \\
\text { logical distress in children } \\
\text { following surgery utilizing the } \\
\text { PTSDSSI and the PCASS }\end{array}$ & $\begin{array}{l}\text { Parents of } 79 \text { children (aged } \\
1-6)\end{array}$ & $\begin{array}{l}\text { A significant portion of children } \\
\text { suffer from psychological dis- } \\
\text { tress } 3-5 \text { months after hospi- } \\
\text { talization }\end{array}$ \\
\hline Stoddard et $a^{38}$ & $\begin{array}{l}\text { Evaluation of PTSD diagnosis } \\
\text { and symptoms utilizing DICA-P } \\
\text { module and the PTSDSSI }\end{array}$ & 42 families & $\begin{array}{l}\text { A high percentage of young } \\
\text { children with burns manifest- } \\
\text { ed some PTSS one month } \\
\text { after discharge. }\end{array}$ \\
\hline
\end{tabular}

PTSS: Posttraumatic stress symptoms, DSM-IV: Diagnostic and Statistical Manual of Mental Disorders, 4th Edition, CTSQ: Child Trauma Screening Questionnaire, HR: Heart rate, CSDC-SF: Child Stress Disorders Checklist-Short Form, PTSD: Posttraumatic stress disorder PICU: Pediatric intensive care unit, PTSD-AA: Alternative PTSD algorithm, PTSDSSI: The PTSD Semi-Structured interview, PCASS: The Preschool Children's Assessment of Stress Scale, DICA-P: The diagnostic interview for children and adolescents

nation of PTSD diagnostic status. The first 17 CPSS items correspond to the Diagnostic and Statistical Manual of Mental Disorders, 4th Edition (DSM-IV) symptom criteria, rated on a four-point Likert scale ("not at all" to "five or more times a week"). The remaining seven items assess functional impairment from those symptoms, rated as absent or present. The CPSS has shown excellent internal consistency, test-retest reliability, and convergent validity with structured clinical interview measures of PTSD. ${ }^{24}$ On the other hand, the Clinician-Administered PTSD Scale for Children and Adolescents (CAPS$\mathrm{CA})^{25}$ was used in the second sample, which is a semi-structured interview that assesses DSM-IV diagnostic criteria for PTSD. Interviewers evaluate the frequency and intensity of each PTSD symp- tom as well as the impact of these symptoms on developmental, social, and scholastic functioning. Psychometric data indicate good internal consistency for each CAPS-CA subscale, and concurrent validity with other measures of PTSD. Regarding the DSM-IV Diagnostic criteria for PTSD, ${ }^{26}$ they include a history of exposure to a traumatic event and symptoms from each of three symptom clusters: intrusive recollections, avoidant/numbing symptoms, and hyper-arousal symptoms, a fifth criterion concerned duration of symptoms and a sixth criterion stipulated that PTSD symptoms must cause significant distress or functional impairment.

This study concluded that the (DSM-IV) 3-factor model, that contains the factors: DSM-IV re-expe- 
riencing symptoms, DSM-IV avoidance symptoms and DSM-IV arousal symptoms, fit reasonably well for these child data, but several alternative models [two four-factor models: the Numbing model that contains the factors: DSM-IV re-experiencing symptoms, effortful avoidance symptoms, emotional numbing symptoms and DSM-IV arousal symptoms, and separates effortful avoidance from emotional numbing, and the Dysphoria model which contains the factors: DSM-IV re-experiencing symptoms, effortful avoidance symptoms, dysphoria symptoms and arousal symptoms (startle/hypervigilance only), and separates PTSD-specific symptoms from general emotional distress] fit equally well or better suggesting improvements to the current diagnostic criteria for PTSD in children.

Another study ${ }^{27}$ investigated the utility of combining the Child Trauma Screening Questionnaire $(C T S Q)^{28}$ and children's heart rate (HR) (HR was measured in emergency department and 24-h postadmission) to identify children likely to develop PTSS at 1 and 6 months post-injury. The CTSQ is a 10-item measure of child traumatic stress assessing five symptoms of re-experiencing and five symptoms of hyper-arousal. The CTSQ has been shown to have good convergent validity with the Children's Impact of Event Scale and to be predictive of PTSD at 1 and 6 months posttrauma. ${ }^{25}$ The internal consistency was satisfactory. ${ }^{28}$ Children are required to respond yes (scored 1) if they have experienced the symptom since the event or no (scored 0 ) if they have not. Scores $\geq 5$ indicate a positive screen for trauma symptoms. Regarding $\mathrm{HR}$, there might be an association between elevated HR and the development of PTSD due to the fact that during trauma, stress hormones are released which increase blood pressure and heart rate (HR) to prepare the individual's 'fight or flight' response in reaction to aversive stimuli. ${ }^{29}$ In this study, it was found that a combination of the CTSQ plus HR (CTSQ-HR) was better than the CTSQ alone or HR alone at identifying children likely to develop PTSS.

Moreover, Enlow et $\mathrm{al}^{30}$ carried out a study to develop a user-friendly scale that measures traumatic stress responses in injured children based on the Child Stress Disorders Checklist (CSDC), ${ }^{31}$ a 36-item observer-report measure of traumatic stress symptoms. In this scale, the measure consists of one traumatic event item, five immediate response items and 30 symptom items. Each of the symptom items is rated on a three-point scale ( $0=$ "not true," $1=$ "somewhat true," $2=$ "very true"). A prior examination of the $\mathrm{CSDC}$, which included the burn participants, demonstrated reliability and validity of the symptomatology total score. ${ }^{31}$ The researchers managed to create a four-item scale (CSDC-Short Form, CSDC-SF). The CSDC-SF contains the following items: "child reports more physical complaints when reminded of the trauma (headache, stomachache, nausea, difficulty breathing, etc.)", "child avoids doing things that remind him or her of the trauma, child startles easily (for example, he or she jumps when hears sudden or loud noises)" and "child gets very upset if reminded of the trauma". Moreover, it is very short and does not require specialized training for administration or interpretation and demonstrated test-retest reliability and predictive validity comparable to that of the full scale.

Furthermore, a cohort study ${ }^{32}$ explored (1) the diagnosis of PTSD in children and adolescents following PICU admission (6 months post-discharge) and (2) the validity of the DSM-IV PTSD algorithm and alternative PTSD algorithm (PTSD-AA) ${ }^{33}$ in school-aged children and adolescents. With regard to PTSD-AA, ${ }^{33}$ it was developed by modifying DSM-IV PTSD symptom wordings, to make them more objective, behaviorally anchored, and developmentally sensitive to young children. This approach used DSM-IV criteria as a starting point, but modified the criteria and studied the effects of those modifications in a series of studies on young children. The major changes are a modification to lower the requirement for the $C$ criterion (numbing and avoidance items) from three out of seven items to just one out of seven items and the omission of A2 (The person's response involved intense fear, helplessness, or horror). It was more reliable and more valid for diagnosing PTSD in infancy than DSM-IV criteria. ${ }^{34}$

The results of this study showed that the alternative PTSD algorithm (PTSD-AA) excluding Criterion C3 (inability to recall aspects of a trauma) provided the most valid measure of PTSD at 6 months. As for 
the ability of each algorithm to identify children with functional impairment it was revealed that PTSD-AA was more sensitive than DSM-IV PTSD in identifying children with functional impairment and it was more diagnostically valid in school-aged children and adolescents, since the frequency of PTSD-AA diagnosis ( $n=17 ; 29 \%)$ was slightly higher than the frequency of DSM-IV PTSD diagnosis $(n=15 ; 25 \%)$.

What is more, Ari et $\mathrm{al}^{35}$ carried out a study to assess the frequency and characteristics of symptoms of persistent psychological distress in children following surgery, using two parent-report questionnaires that assess PTSS among children aged 1 to 6 . The first one was The Posttraumatic Stress Disorder Semi-Structured Interview (PTSDSSI) ${ }^{36}$ which is concerned with the child's response during and after the traumatic event and includes 29 items with an amount of agreement of 1 to 3 on a Likert scale. The internal consistency of PTSDSSI was good, and a strong correlation was found between PTSDSSI scores and the severity and number of symptoms found in a clinical interview several months later. ${ }^{36}$ The second one was the Preschool Children's Assessment of Stress Scale (PCASS). ${ }^{37}$ This measure is concerned with symptoms of anxiety, fear, sleep difficulties, mood changes, and developmental regression, and includes 29 items with an amount of agreement of 1 to 5 on a Likert scale. The internal consistency of PCASS was good. ${ }^{37}$

The responses to the PTSDSSI indicated that $10.39 \%$ of the children exhibit PTSS and that $28.6 \%$ of parents reported that the child's distress causes dysfunction and adjustment difficulties. The results on the PCASS emphasized the parents' concerns regarding the child's behavior, function and health following hospitalization, with a significant rise between the parents' reports of their conception of the child's state before and after surgery.

Last but not least, another study ${ }^{38}$ investigated the prevalence of PTSD in young children hospitalized for burns 1 month after discharge, using both the diagnostic interview for children and adolescents $\left(\right.$ DICA-P) ${ }^{39}$ module and the PTSDSSI. ${ }^{36}$ The DICA-P addresses six symptoms clusters: meeting criteria for experiencing a traumatic event (A cluster), re-experiencing (B cluster), avoidance (C cluster), numbing/ arousal (D cluster) and persistence of symptoms for over a month with clinically significant impairment ( $E$ and $F$, respectively). It has also been used extensively, including with samples of traumatized children and burn survivors and has demonstrated good reliability and validity. ${ }^{40}$

This study found that 4 of the 42 and 1 of 39 participants who completed the DICA-P and PTSDSSI respectively, met full criteria for a diagnosis of PTSD ( $10 \%$ and $3 \%$, respectively). One more finding was that $27 \%$ of the subjects met partial criteria on the DICA-P versus the $16 \%$ on the PTSDSSI, without impairment. Finally, $67 \%$ of subjects met DICA-P criteria for the re-experiencing cluster and $54 \%$ met the PTSDSSI re-experiencing criteria.

\section{Discussion}

The aim of the present review was to identify and report the existing literature with respect to the aggravating factors and the assessment tools for PTSD in children after hospitalization. After extensive literature search using PubMed, 10 articles were found related to risk factors and 6 related to assessment tools. Regarding the aggravating factors, it was found that they do not only have to do with the cause of hospital admission (traumatic injuries or illness/medical-related), but also with factors related to the general experience of hospitalization. As for the assessment tools, there are tools that provide a quick and reliable screening of children who are in danger of or have already developed PTSD or PTSS. However, future research is required to improve the reliability and validity of the existing tools and make them more user-friendly.

\section{Aggravating Factors}

The results of the ${ }^{10}$ studies showed that there is a variety of aggravating factors associated with the development of PTSD. Specifically, two studies ${ }^{12,17}$ found that hospital admission because of traumatic injuries (e.g. falls, burns) lead to higher risk of developing PTSD than illness/medical-related hospital admission. This may be due to the fact that accidents are more immediate events going along with pain and emergency response that are experienced as frightening and distressing more directly by the child, independent of cognitive development, in 
contrast to severe disease like cancer and diabetes where children do not completely understand the implication of their disease.

Furthermore, three studies ${ }^{16,17,20}$ concluded that parental distress is a very important risk factor. A reason for this might be that the parents' own symptoms prevent them from adequately addressing the children's needs after the traumatic event. However, the children do not receive the protection of an optimal caretaking relationship. Another serious aggravating factor that all healthcare workers should take into account is the length of stay into the hospital and especially in PICU. ${ }^{12,16}$ As length of stay increases, children's event related distress also increases for children admitted for traumatic injuries and illness/medical-related reasons. An additional aggravating factor worth to be analyzed is previous health problems. ${ }^{18}$ Children who suffer from chronic diseases and mainly psychiatric illnesses or have been hospitalized in the past, are extremely susceptible to develop PTSD and the necessary measures should be taken to limit this risk.

\section{Assessment tools}

As for assessment tools, the six studies had some very interesting findings. In particular, in the study of Kassam-Adams et al, ${ }^{22}$ although the DSM-IV factor structure received some support, the stronger support for the four-factor numbing model suggested the distinction between active and passive avoidance symptoms in our conceptualization of child and adolescent PTSD. The four-factor Dysphoria model provided a good fit and the Dysphoria model performed slightly better than the DSM-IV model and its fit was roughly comparable to that of the four factor Numbing model.

Moreover, one more interesting study ${ }^{27}$ concluded that the CTSQ-HR was better than the CTSQ alone or HR alone at identifying children likely to develop PTSD symptoms suggesting that the CTSQ-HR screen may increase identification of children who are at risk to develop PTSD symptoms, enabling deployment of targeted prevention programs. Furthermore, Enlow et $\mathrm{al}^{30}$ managed to create the CSDC-SF, a very short, reliable and valid measure that assesses risk for PTSD in youth following a medical trauma that was derived from the 36-item CSDC. It should be emphasized that the CSDC-SF, due to the ease use has potential for more widespread broad application and future studies should further explore the psychometric properties of this measure so that its validity in diverse settings among different populations may be established.

One more assessment tool that approved valid was the PTSD-AA excluding Criterion C 3 which was used to identify children and adolescents following PICU admission who are in great danger of developing PTSD. ${ }^{32}$ For one more time DSM-IV PTSD lagged in relation to other tools, as PTSD-AA found to be superior to DSM-IV PTSD in young children, was more diagnostically valid in older children and was more sensitive identifying children with functional impairment.

Last but not least, the results of Stoddard's et al study ${ }^{38}$ may offer clues to current diagnoses of PTSD in young children, because PTSDSSI diagnosis is strongly linked to the diagnostic and statistical manual-5 (DSM-5) criteria for "PTSD in children 6 years and younger".

\section{Limitations}

Some limitations of this review should be acknowledged. The greatest limitation - but also significant finding - of this review is the scarceness of published studies on this topic. The participation rate was low in the majority of including studies leading to reduction of generalizability of the results of those studies. Accordingly, the generalization of the findings of the present review should be interpreted with caution.

\section{Conclusions}

This review concluded that there is a variety of aggravating factors associated with the development of PTSD in children after hospitalization that all the healthcare workers should know in order to take the necessary precautionary measures to reduce the risk of developing PTSD. Assessment tools should provide a quick and reliable screening to identify immediately the children who are likely to or have already developed PTSD or PTSS. 


\title{
Emißapuvtukoí mapáyovtes

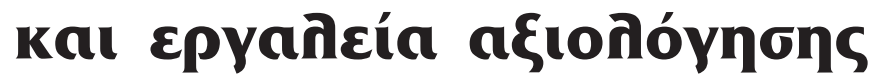

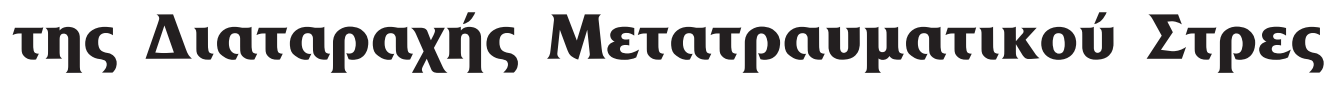

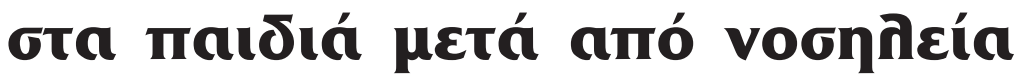

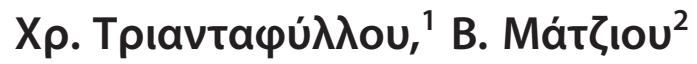

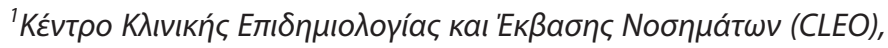

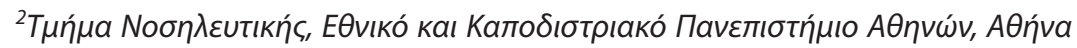

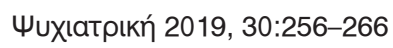

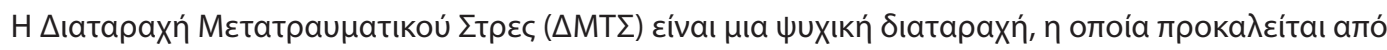

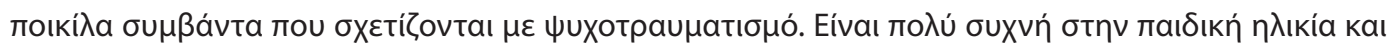

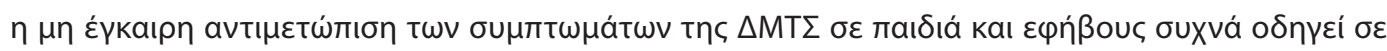

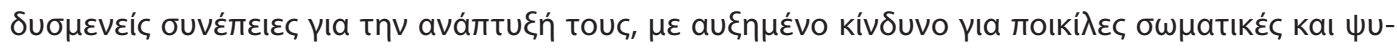

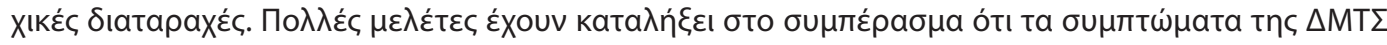

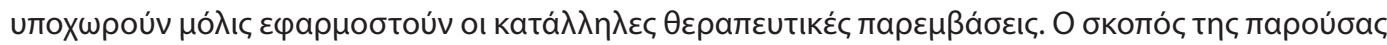

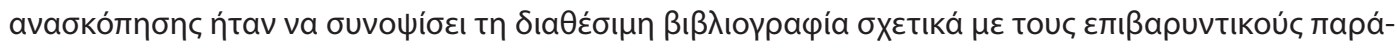

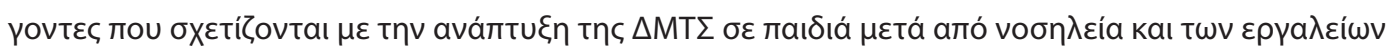

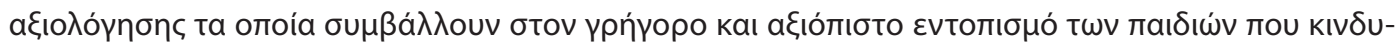

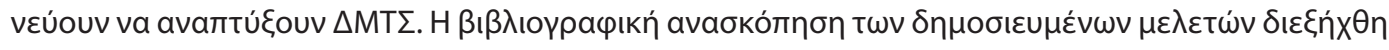

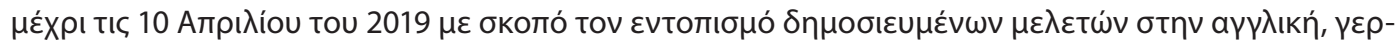

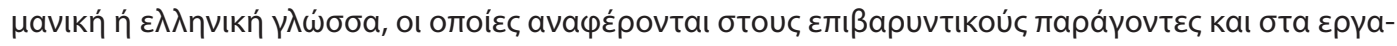

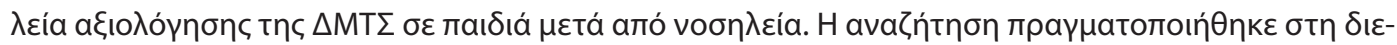

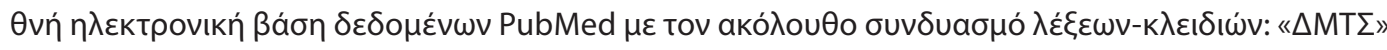
кal «таıठ

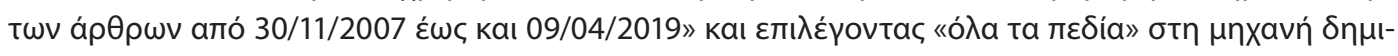

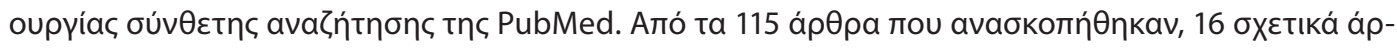

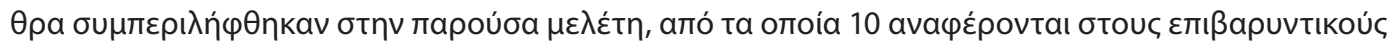

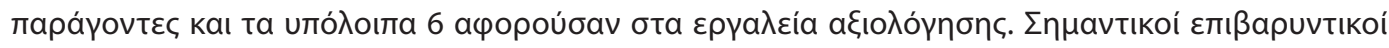

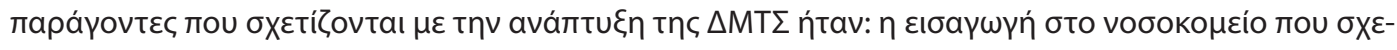

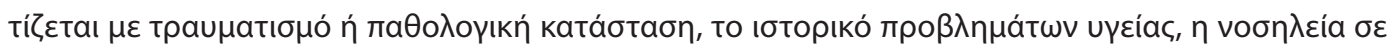

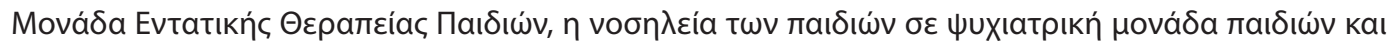

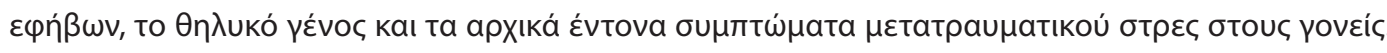

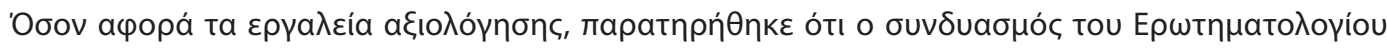

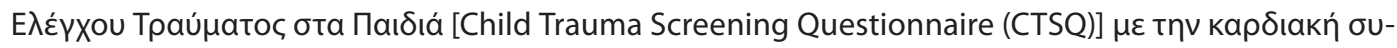

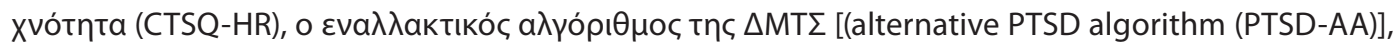

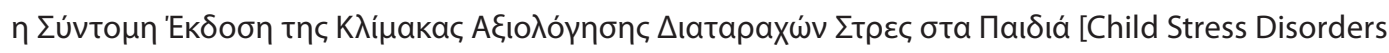

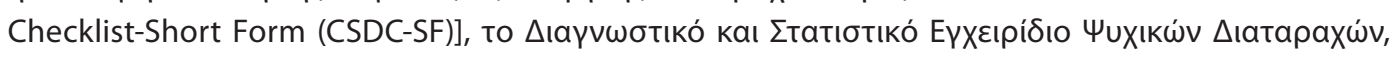

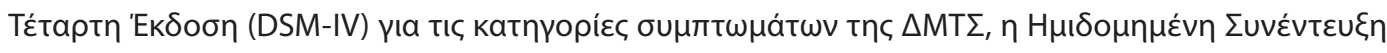

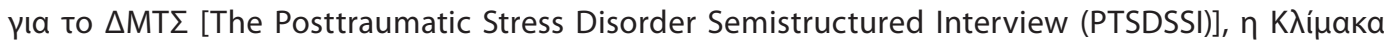

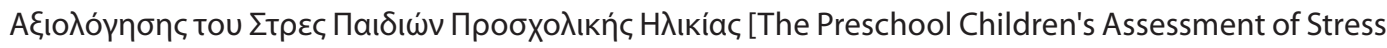

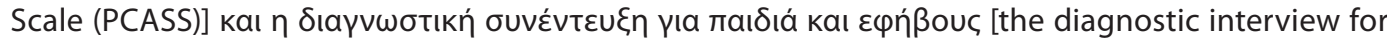

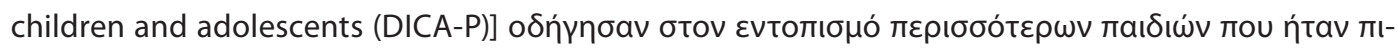

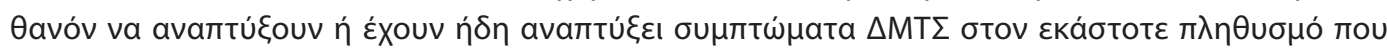




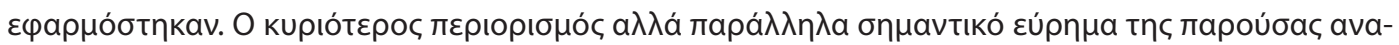

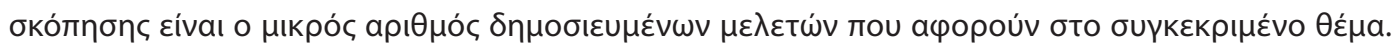

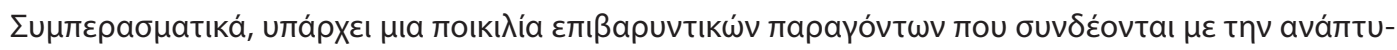

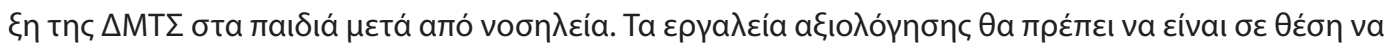

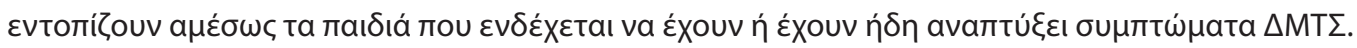

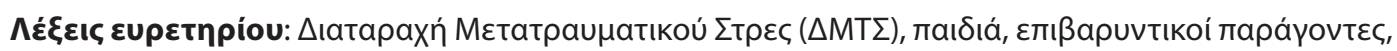

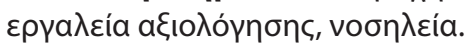

\section{References}

1. Kassam-Adams N, Winston FK. Predicting Child PTSD: the relationship between acute stress disorder and PTSD in injured children. J Am Acad Child Adolesc Psychiatry 2004, 43:403-411, doi: 10.1097/00004583-200404000-00006

2. Kazak AE, Kassam-Adams N, Schneider S, Zelikovsky N, Alderfer MA, Rourke M. An Integrative Model of Pediatric Medical Traumatic Stress. J Pediatr Psychol 2005, 31:343-355, doi: 10.1093/jpepsy/jsj054

3. Landolt M, Vollrath M, Laimbacher J, Gnehm H, Sennhauser F. Prospective Study of Posttraumatic Stress Disorder in Parents of Children with Newly Diagnosed Type 1 Diabetes. J Am Acad Child Adolesc Psychiatry 2005, 44:682-689, doi: 10.1097/01.chi. 0000161645.98022 .35

4. Cohen JA, Mannarino AP, Berliner L, Deblinger E. Traumafocused cognitive behavioral therapy for children and adolescents: an empirical update. J Interpers Violence 2000, 15:12021223, doi: https://doi.org/10.1177/088626000015011007

5. Carrion VG, Weems CF, Eliez S, Patwardhan A, Brown W, Ray $\mathrm{RD}$ et al. Attenuation of frontal asymmetry in pediatric posttraumatic stress disorder. Biol Psychiatry 2001, 50:943-951, PMID: 11750890

6. De Bellis M, Keshavan M, Clark D, Casey B, Giedd J, Boring A et al. Developmental traumatology part II: brain development. Biol Psychiatry 1999, 45:1271-1284, doi: https://doi.org/10.1016/ S0006-3223(99)00045-1

7. Seng J. Posttraumatic Stress Disorder and Physical Comorbidity among Female Children and Adolescents: Results from ServiceUse Data. Pediatrics 2005, 116: e767-776, doi: 10.1542/peds. 2005-0608Saunders

8. Berliner L, Hanson R. Child physical and sexual abuse guidelines for treatment. Charleston. SC: National Crimes Victims Research and Treatment Center 2003 (Cited 20 November 2017). Available from eric.ed.gov/? id=ED472572

9. Shalev A, Bonne O, Eth S. Treatment of Posttraumatic Stress Disorder: a review. Psychosom Med 1996, 58:165-182, PMID: 8849635

10. Ziegler M. Posttraumatic Stress Responses in Children: Awareness and Practice among a Sample of Pediatric Emergency Care Providers. Pediatrics 2005, 115:1261-1267, doi: 10.1542/peds. 2004-1217

11. Banh M, Saxe G, Mangione T, Horton NJ. Physician-reported practice of managing childhood posttraumatic stress in pediatric primary care. Gen Hosp Psychiatry 2008, 30:536-545, doi: 10.1016/j.genhosppsych.2008.07.008

12. Murray B, Kenardy J, Spence S. Brief Report: Children's Responses to Trauma- and Nontrauma-related Hospital
Admission: A Comparison Study. J Pediatr Psychol 2007, 33:435-440, doi: 10.1093/jpepsy/jsm078

13. Rosenberg L, Rosenberg M, Robert R, Richardson L, Sharp S, Holzer CE et al. Does Acute Stress Disorder Predict Subsequent Posttraumatic Stress Disorder in Pediatric Burn Survivors? J Clin Psychiatry 2015, 76:1564-1568, doi: 10.4088/JCP.14m09365

14. Bruce M, Gumley D, Isham L, Fearon P, Phipps K. Posttraumatic stress symptoms in childhood brain tumour survivors and their parents. Child Care Health Dev 2010, 37:244-251, doi: 10.1111/j.1365-2214.2010.01164.x

15. Münzer A, Fegert J, Goldbeck L. Traumaanamnese und posttraumatische Stresssymptomatik in einer kinder- und jugendpsychiatrischen Inanspruchnahmepopulation. Psychiat Prax 2014, 42:96-101, doi: 10.1055/s-0033-1360058

16. Rennick J, Rashotte J. Psychological outcomes in children following pediatric intensive care unit hospitalization: a systematic review of the research. $J$ Child Health Care 2009, 13:128-149, doi: $10.1177 / 1367493509102472$

17. Landolt MA, Ystrom E, Sennhauser FH, Gnehm HE, Vollrath ME. The mutual prospective influence of child and parental post-traumatic stress symptoms in pediatric patients. J Child Psychol Psychiatry 2011, 53:767-774, doi: 10.1111/j.1469-7610. 2011.02520.x

18. Als LC, Picouto MD, O'Donnell KJ, Nadel S, Cooper M, Pierce $\mathrm{CM}$ et al. Stress hormones and posttraumatic stress symptoms following paediatric critical illness: an exploratory study. Eur Child Adolesc Psychiatry 2016, 26:511-519, doi: 10.1007/s00787-0160933-3

19. Dow BL, Kenardy JA, Long DA, Le Brocque RM (2019). Cognitive/ affective factors are associated with children's acute posttraumatic stress following pediatric intensive care. Psychol Trauma 2019, 11:55-63, doi: 10.1037/tra0000349

20. Stowman S, Kearney C, Daphtary K. Mediators of Initial Acute and Later Posttraumatic Stress in Youth in a PICU*. Pediatr Crit Care Med 2015, 16:e113-e118, doi: 10.1097/PCC.0b013e31822f1916

21. Alisic E, Zalta A, van Wesel F, Larsen S, Hafstad G, Hassanpour K et al. Rates of post-traumatic stress disorder in trauma-exposed children and adolescents: meta-analysis. Br J Psychiatry 2014, 204:335-340, doi: 10.1192/bjp.bp.113.131227

22. Kassam-Adams N, Marsac M, Cirilli C. Posttraumatic Stress Disorder Symptom Structure in Injured Children: Functional Impairment and Depression Symptoms in a Confirmatory Factor Analysis. J Am Acad Child Adolesc Psychiatry 2010, 49:616-625. e4, doi: 10.1016/j.jaac.2010.02.011

23. Foa EB, Johnson KM, Feeny NC, Treadwell KRH. The Child PTSD Symptom Scale: a preliminary examination of its psychometric 
properties. J Child Clin Psychol 2001, 30:376-384, doi: 10.1207/ S15374424JCCP3003_9

24. Foa EB, Johnson KM, Feeny NC, Treadwell KRH. The Child PTSD Symptom Scale: a preliminary examination of its psychometric properties. J Child Clin Psychol 2001, 30:376-384, doi: DOI: 10.1207/S15374424JCCP3003_9

25. Nader K, Kriegler JA, Blake DD, Pynoos RS, Newman E, Weathers FW. Clinical administered PTSD scale, child and adolescent version. White River Junction, VT: National Center for PTSD; 1996

26. GUZE S. Diagnostic and Statistical Manual of Mental Disorders, 4th ed. (DSM-IV). Am J Psychiatry 1995, 152:1228-1228, doi: https://doi.org/10.1176/ajp.152.8.1228

27. Olsson KA, Kenardy JA, De Young AC, Spence SH. Predicting children's post-traumatic stress symptoms following hospitalization for accidental injury: Combining the Child Trauma Screening Questionnaire and heart rate. J Anxiety Disord 2008, 22:14471453, doi: 10.1016/j.janxdis.2008.02.007

28. Kenardy J, Spence S, Macleod A. Screening for Posttraumatic Stress Disorder in Children After Accidental Injury. Pediatrics 2006, 118:1002-1009, doi: 10.1542/peds.2006-0406

29. Yehuda R, McFarlane A, Shalev A. Predicting the development of posttraumatic stress disorder from the acute response to a traumatic event. Biol Psychiatry 1998, 44:1305-1313, PMID: 9861473

30. Bosquet Enlow M, Kassam-Adams N, Saxe G. The Child Stress Disorders Checklist-Short Form: a four-item scale of traumatic stress symptoms in children. Gen Hosp Psychiatry 2010, 32:321327, doi: 10.1016/j.genhosppsych.2010.01.009

31. Saxe G, Chawla N, Stoddard F et al. Child Stress Disorders Checklist: a measure of ASD and PTSD in children. J Am Acad Child Adolesc Psychiatry 2003, 42:972-978, doi: 10.1097/01. CHI.0000046887.27264.F3

32. Dow BL, Kenardy JA, Le Brocque RM, Long DA. The Diagnosis of Posttraumatic Stress Disorder in School-Aged Children and Adolescents Following Pediatric Intensive Care Unit Admission. J Child Adolesc Psychopharmacol 2013, 23:614-619, doi: 10.1089/ cap.2013.004
33. Scheeringa M, Zeanah C, Cohen J. PTSD in children and adolescents: toward an empirically based algorithm. Depress Anxiety 2010, 28:770-782, doi: 10.1002/da.20736

34. Scheeringa M, Zeanah C, Drell M, Larrieu J. Two Approaches to the Diagnosis of Posttraumatic Stress Disorder in Infancy and Early Childhood. J Am Acad Child Adolesc Psychiatry 1995, 34:191-200, doi: 10.1097/00004583-199502000-00014

35. Ari A, Peri T, Margalit D, Galili-Weisstub E, Udassin R, Benarroch F. Surgical procedures and pediatric medical traumatic stress (PMTS) syndrome: Assessment and future directions. J Pediatr Surg 2018, 53:1526-1531, doi: 10.1016/j.jpedsurg.2017.10.043

36. Scheeringa MS, Zeanah CH. PTSD semi-structured interview and observational record for infants and young children. New Orleans: Department of Psychiatry and Neurology, Tulane University Health Sciences Center; 1994

37. Laor N. Israeli Preschoolers Under Scud Missile Attacks. Arch Gen Psychiatry 1996, 53:416, PMID: 8624185

38. Stoddard F, Sorrentino E, Drake J, Murphy J, Kim A, Romo S et al. Posttraumatic Stress Disorder Diagnosis in Young Children With Burns. J Burn Care Res 2017, 38:e343-e351, doi: 10.1097/ BCR. 0000000000000386

39. Reich W. Diagnostic interview for children and adolescents (DICA). J Am Acad Child Adolesc Psychiatry 2000, 39:59-66, doi: 10.1097/BCR.0000000000000386

40. Pollio ES, Glover-Orr LE, Wherry JN. Assessing posttraumatic stress disorder using the trauma symptom checklist for young children. J Child Sex Abus 2008, 17:89-100, PMID: 19842320

Corresponding author: Chr. Triantafyllou, 107 Andrianoupoleos street, GR-122 42 Egaleo, Attica, Greece, Tel: (+30) 6971-842 775

e-mail: christriantafyllou494@gmail.com 